\title{
Erratum to: Topographic Evaluation of the Medial Canthus- Alar Groove Line in Terms of Determining the Boundaries of Lateral Osteotomies
}

\author{
Mustafa Tercan · Guray Yesiladali • \\ Sinem Ciloglu $\cdot$ Kaan Meric
}

Published online: 23 April 2013

(c) Springer Science+Business Media New York and International Society of Aesthetic Plastic Surgery 2013

\section{Erratum to: Aesth Plast Surg (2013) 37:34-38 \\ DOI 10.1007/s00266-012-9985-z}

The following errors were observed after the article was published:

(1) All of the authors were working at the same institution when the study was performed: Department of Plastic, Reconstructive, and Aesthetic Surgery, Haydarpasa Numune Training and Research Hospital—not the Gaziantep Dr. Ersin Arslan Hospital.

(2) The first author, Mustafa Tercan, is affiliated with Highschool of Health Professions, Kirklareli University.
(3) The third author, Sinem Ciloglu, is affiliated with Department of Plastic, Reconstructive, and Aesthetic Surgery, Haydarpasa Numune Training and Research Hospital.

The online version of the original article can be found under doi:10.1007/s00266-012-9985-z.

M. Tercan · G. Yesiladali · S. Ciloglu · K. Meric

Department of Plastic, Reconstructive, and Aesthetic Surgery,

Haydarpaşa Numune Research and Training Hospital, Istanbul,

Turkey

M. Tercan

Highschool of Health Professions, Kırklareli University,

Kirklareli, Turkey

Present Address:

G. Yesiladali $(\square)$

Gaziantep Dr. Ersin Arslan Hospital, Gaziantep, Turkey

e-mail: gyesiladali@gmail.com

\section{K. Meric}

Radiology Department, Haydarpaşa Numune Research and

Training Hospital, Istanbul, Turkey 